Abstracta Iranica Abstracta Iranica

Revue bibliographique pour le domaine irano-aryen

Volume 29 | 2008

Comptes rendus des publications de 2006

\title{
Rythmic Structure in Iranian Music. Tehran, University of Art, 2006, XXXv + 362 p. ill. Index, transcriptions, $1 \mathrm{CD}$.
}

\section{Sāsān Fāțemī}

\section{(2) OpenEdition}

1 Journals

Édition électronique

URL : http://journals.openedition.org/abstractairanica/33642

DOI : 10.4000/abstractairanica.33642

ISSN : 1961-960X

Éditeur :

CNRS (UMR 7528 Mondes iraniens et indiens), Éditions de l'IFRI

\section{Édition imprimée}

Date de publication : 15 mai 2008

ISSN : 0240-8910

Référence électronique

Sāsān Fāțemī, « Rythmic Structure in Iranian Music. Tehran, University of Art, 2006, xxxv + 362 p. ill. Index, transcriptions, 1 CD. », Abstracta Iranica [En ligne], Volume 29 | 2008, document 434, mis en ligne le 15 septembre 2008, consulté le 26 septembre 2020. URL : http://journals.openedition.org/ abstractairanica/33642 ; DOI : https://doi.org/10.4000/abstractairanica.33642

Ce document a été généré automatiquement le 26 septembre 2020.

Tous droits réservés 


\title{
Rythmic Structure in Iranian Music. Tehran, University of Art, 2006, xxxv +362 p. ill. Index, transcriptions, $1 \mathrm{CD}$.
}

\author{
Sāsān Fāțemī
}

1 Il s'agit de la publication de la thèse du doctorat de l'auteur. L'ouvrage comporte six chapitres regroupés en trois parties, plus un appendice sur la représentation et la transcription du rythme dans la musique iranienne. La première partie présente la structure rythmique de la poésie persane et les cycles rythmiques tels qu'ils apparaissent dans les traités anciens sur la musique. La deuxième partie examine, en deux chapitres, la structure rythmique du radiff et celle des genres pré-composés dans la musique iranienne et la dernière partie se focalise sur la pratique musicale concernant le rythme. L'A. a identifié, sur le plan rythmique, trois types de gūše dans le radîf (les gūše mesurés, les gūše non mesurés et ceux qui suivent une métrique flexible) et a essayé de faire correspondre leurs principes rythmiques à ceux de la métrique poétique et des cycles rythmiques dont il a donné une liste très utile dans la première partie. Pour chaque notion il a analysé minutieusement quelques fragments du radif souvent en présentant plus d'une version de chaque gūše.

2 Malheureusement il n'a pas consulté le très important traité de Fārābī sur le rythme, Ketāb al-İ $\bar{q} \bar{a} \bar{a} t$ dont la traduction était disponible dans le numéro 23 (printemps 2004) du Fașl-nāme-ye mūsīqi-ye Māhūr et qui aurait pu lui inspirer une méthode d'analyse plus appropriée. De plus, il ne va pas quelquefois jusqu'au bout de ses analyses et ne justifie pas ses conclusions (par exemple, il insiste sur la fonction structurante de certains types du tahrir sans expliquer concrètement cette fonction). 
INDEX

Thèmes : 17.1.Musique

\section{AUTEURS}

SĀSĀN FĀTEMĪ

Université de Téhéran 